\title{
Supply Chain Management in a Global Pandemic
}

\author{
Pavel Sizov*, and Zinaida Khmelnitskaya \\ Ural State University of Economics
}

\begin{abstract}
The article is devoted to the actual problems of supply chain management in the context of a pandemic. The difficulties faced by transport and logistics systems are considered in general. We described digital technologies, the timely introduction of which helped to maintain the sustainability of supplies, especially regarding the supply of food, personal hygiene and protection products, and medicines. The principles of testing the effectiveness of the implementation of digital technologies and methods in supply chain management were formulated. We proposed a methodology and a logical scheme, which enables to build and analyze a model of the network structure of supply chains, to identify "pain points" in supply chains to maintain the sustainability of the system. The practical approbation of the proposed approach was carried out.
\end{abstract}

\section{Introduction}

The pandemic has disrupted established supply chains around the world. This resulted in logistical problems in various industries. To solve the problems that have arisen, operational transformations are needed, which are based on modern technologies and human resources, as well as communications and information flows that connect them. The importance of logistics has been highlighted by the global crisis due to the worldwide spread of the coronavirus - from the supply of personal protective equipment to medical workers to restocking in supermarkets. There has been a significant reduction in the volume of freight transportation by air and sea, a change in the structure of consumption, and a rapid transition from shopping in stores to e-commerce.

Today, more than ever, many companies are trying to take advantage of their competitive advantages by rationalizing their supply chains. Applied software solutions can detect when there is a shortage of goods in the warehouse, as well as identify the source of the problem caused by the delivery on the route, warehouse situation, or change in the order volume. During the global COVID-19 pandemic, supply chains began to modernize so rapidly that the issue of creating universal models that reflect the real state of processes in any situation is particularly acute. Companies increase the responsiveness to customer needs, meet their requirements for delivering the right product to the right place at the right time, build a model of the logistics network and create a system of its information support, which in turn already forms the economic and mathematical apparatus, and such digital

\footnotetext{
* Corresponding author: pavel@sizov.net
} 
technologies as blockchain, an introduction of sensors for recording events and transmitting information online, web technologies, cloud technologies, distributed data exchanges, storage and processing of big data, the concept of artificial intelligence, etc. can be applied.

\section{Materials and Methods}

Four key logistical challenges need to be addressed.

1. The capacity of the logistics market has decreased. Prior to the pandemic, shipping usually accounts for about $90 \%$ of global trade. But the pandemic first led to a reduction in the supply of manufactured goods from Asia, then swept around the world and led to a sharp drop in demand for goods delivered by sea. Sea carriers responded by removing opportunities for sea transportation from the market: shipping cancellations began. Air freight capacity has also fallen in large part due to the fact that a significant portion of air freight passes through passenger flights, many of which were canceled due to the cessation of passenger traffic. Meanwhile, driver shortages and cross-border restrictions have led to reduced road capacity in certain locations and long delays. Currently, the freight transportation market is beginning to stabilize. Meanwhile, a number of other questions have emerged:

- Moving sea freight into the air, despite higher shipping rates and a struggle for space. Manufacturers of technology products - laptops and headsets - have faced a sharp increase in demand as millions of people around the world have left the office and started working from home for a long time;

- Use of charters for urgent high-value freight that would otherwise end up on board of freight planes or in the cabin of wide-body passenger flights;

- Conversion of empty passenger aircraft into "freight and passenger liners" that can carry freight in specially packed passenger cabins, in addition to freight on the belly;

- Separation of charters and consolidation of freight between freight forwarders or shippers, who can usually be competitors;

- Alternative modes of transport, such as rail transport from China to Europe, and then long-distance freight transport across borders;

- Alternative airports, ports, and freight transportation routes with additional options.

2. The pandemic has revealed the emergence of unsustainable demand. COVID19 has accelerated the transition of consumers to online shopping. In Italy, sales of consumer goods through e-commerce increased by $81 \%$ in one week. McKinsey predicts that $55 \%$ of consumers in China will continue to shop online even as the crisis eases. Now consumers around the world buy cars without even visiting the exhibition hall, although just 2 years ago this situation was difficult to imagine. The takeaway retail approach creates logistical hurdles. E-commerce requires fast execution and delivery, which are also inexpensive for the consumer. Solutions include alternative inventory storage: additional storage facilities near the point of departure or destination, conversion of stores into storage facilities as distribution and order fulfillment centers, or strategic use of sea freight transportation as a "floating storage" through careful timing of orders and deliveries. [11]

3. Geographical risks. The crisis has forced a reassessment of the location of supply chains. At the beginning of the pandemic, when China stopped production, there were interruptions in the supply of a large range of goods around the world. Many companies find it difficult to sever or weaken ties with China. The supply chains there are very efficient, the workforce is large and skilled, the market 
is vast and growing. Chinese manufacturing is deeply integrated with manufacturing resources and production in other Asian markets.

4. The need to modernize the inventory management system. There have been changes in consumer demand, which fluctuate in the supply chain to an increasing extent, creating long-term problems for production and supply. This can be assessed by one-time sharp jumps in demand for certain types of goods - one week there is a shortage, and the next excess stocks. From delayed goods to goods that have already lost relevance, the pandemic has created havoc in stocks. [11]

Despite the easing of restrictions after the end of the pandemic, some social and economic aspects (such as visiting restaurants, cinemas, and other public places) are likely to be significantly affected as people order food and other goods online. Online food purchases will also continue to gain momentum. In this scenario, the importance of logistics and the sustainability of supply chains increase many times. [12]

Not only consumers are expected to buy more local products for fear of catching viruses from imported products, but many governments will maintain border restrictions on the movement of goods between countries. For this purpose, when modeling supply chains, we should consider moving away from the concept of long-distance trade and moving supplies closer to the consumer. This will continue to ensure timely delivery and subsequently contribute to a gradual increase in demand for products.

In the study "VALUE CHAINS IN THE CONTEXT OF THE COVID-19 PANDEMIC", the authors also point to problems in global supply chains in connection with the pandemic. It is noted that it is necessary to introduce modern technologies to increase diversification in logistics systems to reduce vulnerability to "global shocks". [1]

"The problems with supply chain failures that have arisen have shown the importance of avoiding clustering of suppliers in one region, moving to an outsourcing (contract) model of interaction with short- and medium-term obligations up to the dropshipping function of establishing sales of a direct manufacturer". [3]

The processes of global digital transformation of socio-economic processes (including in logistics) are described in their study by Kurbanov A.Kh., Plotnikov V.A.: "There can be no doubt that the digital transformation is taking place. As it was shown above, the foreseeable future involves the global digitalization of all processes that are designed to ensure the life of people. And it's not just logistics..." [2]

In their paper "International Supply Chains: New Trends in the Context of the Coronavirus Pandemic", the authors point to a serious destructive process that is taking place in the international supply chain. Supply chains will never be the same again, and after the end of the pandemic, they will be subject to a major transformation. The vulnerability of global supply chains is proven by the fundamental shock to the global financial and economic systems. The pandemic will have long-term economic consequences. The important role of China as the starting point of material flow in the global supply chain will also be reviewed due to the huge risks. In the coming years, the global supply chain will be transformed based not so much on the principle of increasing profits for the chain participants but the principle of sustainability of the entire system as a whole. [4]

Many foreign and domestic scientists quickly responded to the problems in logistics and began to consider their work with effective methods of modernization of logistics networks and introduction of digital technologies in supply chain management. Many scientists are concerned about the introduction of digital technologies in logistics systems. This problem was considered in their papers by Afanasenko D.A., Basansky M.V., Borisova V.V., Gorsky D.V., Krasnoperova M.V., Kokurin D.I., Kuprianovskaya Yu.V., Kuprianovsky V.P., Larin O.N., 
Lysenko M.V., Lysenko Yu.V., Matveev V.V., Nemanova A.N., Rozhko O.N., Sergeev V.I., etc.

Basansky M.V. discusses in his research the need for centralization, standardization, and automation of procurement activities, and also points to the relevance of the introduction of modern information systems for automating procurement activities at enterprises. This approach will open up new opportunities for the supply chain management. However, it is impossible without the introduction of digital technologies and the creation of modern information systems to quickly and accurately process the resulting large amount of information. [6]

Krasnoperova M.V., Matveev V.V. describe in their research the trend of the introduction of the Internet in logistics, which increases the transparency of the transportation process for the end customer. [7]

In the paper "Conceptual Foundations of Supply Chain Management in E-commerce", it is indicated that modern technologies and information systems for supply chain management are a resource for reducing logistics costs. [5]

In the study "Integrated Approach to the Digital Transformation of Intermodal Container Transport", Nemanova A.N. considers the transition to digital business for logistics companies: "The main requirement of an integrated approach to the digital transformation of intermodal container transportation is to take into account the interaction of both internal and external factors that determine the formation of a complex benefit". [8]

A number of authors $[13,14]$ point to the need to introduce digital blockchain technology. This technology generates and processes a digital register of transactions with certain assets in several places at the same time. The main principal feature of the introduction of blockchain technology is the uninterrupted provision of information transfer between the participants of the supply chain. This technology should facilitate easier and safer decision-making at every stage of the production and delivery process. This technology is beginning to be actively used in transport logistics to ensure the transparency of freight operations throughout the supply chain, the integration of market, commercial, and production information to reduce risks and transit to intelligent and paperless technologies for all participants in economic turnover.

Despite the variety of digital technologies described above for their application in logistics systems and supply chain management, the issues and methods of modeling logistics systems, building information systems for supply chain management remain poorly researched. There is also little research on how exactly and at what stages to implement digital technologies, when their implementation may not bring a positive effect.

\section{Results and Discussion}

According to the authors, to create effective supply chain management software, first of all, it is necessary to build a high-quality simulation model of the network structure of supply chains, form an information support system in supply chains, and only then make decisions about the implementation of technologies and create an information system for analysis and management. The task of creating an information support system for the network structure of supply chains is carried out in practice for a specific object of research - an economic entity, a functional area, etc. The authors propose the use of a logical scheme (Figure 1) and a methodological approach for the analysis and formalization of information flows, structural detailing of relationships in the network structure, and creation of a simulation model. In practice, this approach enables to build information support for the network structure of supply chains and solve specific tasks for various logistics systems of the selected research objects. As mathematical methods for solving optimization problems in 
practice, the authors used mathematical methods for solving problems on directed graphs. $[9,10]$

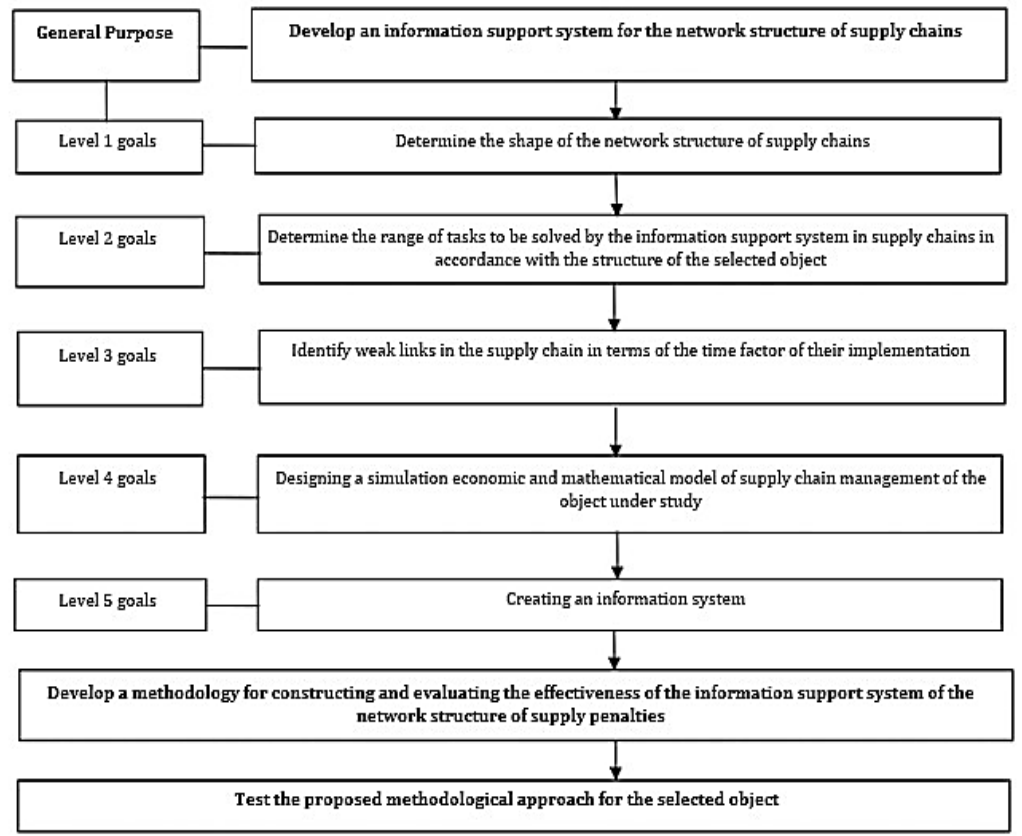

Fig. 1. Logical scheme for building an information support system for the network structure of supply chains.

When forming a logistics network, all elements of location, customer market, personnel reserve, quality of life requirements, and government incentives will be taken into account. The analysis of the above factors will allow us to create models that will give companies a deeper understanding of the choice of the structure of the logistics network.

The introduction of modern digital technologies in the supply chain enables companies to dynamically participate in modeling problems and further solving them. When developing information support for the network structure of supply chains according to the logical scheme (Figure 1), a simulation economic and mathematical model of supply chain management is built, on which an information system for management and decisionmaking will be based. In fact, this system with the physical implementation of digital sensors will be a digital twin for the logistics system under study.

The real-time digital twin concept can be an innovation that will enable dynamic realtime modeling and process optimization before any real changes are needed to minimize the risk of supply chain changes.

\section{Conclusions}

The proposed methodology for developing an automated system of information support for the network structure of supply chains has shown its validity in practical testing on specific research objects - a retail chain, a manufacturing enterprise, and an international logistics company.

Companies should be mindful of changing consumer behavior after the pandemic. Agile and innovative companies will lead the way as they can quickly experiment, evaluate, 
implement, track and optimize processes and resources, and apply new technologies to mitigate impacts and meet changing market conditions. [12]

Advances in digital technology allow organizations, with relatively small investments, to quickly increase efficiency in supply chain management, which can give a competitive advantage in the market. However, it is worth noting that the attractiveness of these technologies has resulted in some companies began to hastily implement everything in a row, without having a verified system of tasks to be solved by implementing a specific technology. Ultimately, such a choice can lead the digitalization project to a dead end. It shall be recognized that the digital transformation of supply chains shall be carried out following a verified algorithm of actions, analysis, and strictly following the list of planned activities. Companies that use this approach are more likely to have the positive impact that digital technologies promise.

It is important to consider all the technologies and invest them in the architecture of the information system at the modeling stage, to assess in which issues their use is necessary and justified. When implementing any technology, we need to keep in mind the ecosystem of the planet, the global trend of green logistics in parallel with the trend of digital logistics.

\section{References}

1. O.V. Ponomareva, T. A. Flegontova, Economic development of Russia, 27(10) (2020)

2. A. Kh. Kurbanov, V. A. Plotnikov, Bulletin of The St. Petersburg State University of Economics (2020)

3. O. N. Voronkova, Innovation and Investment, 1 (2021)

4. I. V. Boyko, A. G. Hetman, Management consulting, 11, 42 (2020)

5. D.V. Gorsky, Conceptual Foundations of Supply Chain Management in E-commerce

6. A. N. Nemanova, Integrated Approach to the Digital Transformation of Intermodal Container Transport

7. P. L. Sizov, Z. B. Khmelnitskaya, Economics and Entrepreneurship, 8(109), 1159 (2019)

8. M. O. Asanov, V. A. Baransky, V.V. Rasin, Discrete mathematics: matroid graphs algorithms, 288 (2001)

9. Agility Insights, https://logisticsinsights.agility.com

10. Mindtree, https://www.mindtree.com

11. Yu. V. Lysenko, M. V. Lysenko, R. I. Garipov, Azimuth of Scientific Research: Economics and Management, 8, 3(28) (2019)

12. Yu. V. Kuprianovskaya, V. P. Kuprianovsky, A. A. Klimov, D. E. Namiot, A.V. Dolbnev, S. A. Sinyagov, Yu. P. Lipuntsov, A. G. Arsenyan, S. N. Yevtushenko, O. N. Larin, Int. J. of Open Information Technologies, 6(3) 2018 